\title{
Design and Manufacturing of Leaf and Coil Suspension
}

\author{
V. Chandra Bose ${ }^{1}$, V. Rajasimman ${ }^{2}$, R. Gokul Prabu ${ }^{3}$, K. Har Govind ${ }^{4 *}$ \\ ${ }^{1}$ Assistant Professor, Department of Mechanical Engineering, KGISL Institute of Technology, Coimbatore, India \\ ${ }^{2,3,4}$ Student, Department of Mechanical Engineering, KGISL Institute of Technology, Coimbatore, India \\ *Corresponding author: hargovindkesavan@gmail.com
}

\begin{abstract}
The suspension system of an automobile separates the wheel/axle assembly from the body. The primary function of the suspension system is to isolate the vehicle structure from shocks and vibration due to irregularities of the road surface and to maintain contact with the surface thereby providing traction and control. Leaf spring is the preferred type of suspension system in almost all light and heavy commercial and transport vehicles. Leaf spring used in many vehicles due to having some main characteristics which are economical construction, uniformly distributed load, simple assembly in the vehicle and forgiving on use in rough terrain. In this paper we would like to take a look on the leaf spring, its design parameters and analysis. The paper is based on material selection, designing, experimental testing and load analysis etc.
\end{abstract}

Keywords: ANSYS, Compositions, Experiments, Leaf spring, Material, Mathematics.

\section{Introduction}

A leaf spring is one of the earliest form of spring and it is commonly used for the suspension in vehicles. Although you may not ever have heard about or even noticed leaf springs on larger tow vehicles, the technology has been around for centuries and is one of the earliest forms of suspension. Even Leonardo da Vinci used leaf springs in his diagram for a selfpropelled car. Leaf spring is traditionally made using spring steel but advances in material sciences have enabled the use of composite materials in customized use case scenarios. Although Composite materials offer significant reduction in weight they are highly specialized and require expertise in manufacturing. The composite materials used like Fiber Glass/Epoxy, Carbon fibers/Epoxy etc. The main classification of leaf spring are as follows, Elliptical, Semi Elliptical, Three quarter Elliptical, Quarter Elliptical, and TerraServer's. The leaf spring consists of parts like master leaf, center bolt, central 'U' clamp, Eye. The suspension system also offers directional stability. This implies that the vehicle should have tendency to return to its straight ahead position after turning and it should provide pure rolling motion to wheel.

\section{How Leaf Spring Work}

Leaf springs are long bundles of spring material that flex under pressure from the movement of a vehicle's axle. The ends of the leaf spring bundle are attached to the chassis of the car or truck, and the axle is then attached to the center of the leaves. When the axle moves on various road conditions, the leaves compress and absorb the motion rather than transferring all the energy directly to the chassis.

If there's too much weight weighing down for a softly sprung suspension, causing everything to rock and sway, the issue may be rectified by increasing spring stiffness. If a Design and Analysis of Leaf Spring by Using Composite Material for Light Vehicles truck's suspension is too rigid, its wheels will often leave the pavement after hitting bumps; a good suspension, on the other hand, keeps the wheels on the ground as much as possible. Many vehicles use leaf springs to stabilize their towed load and to keep their cargo grounded.

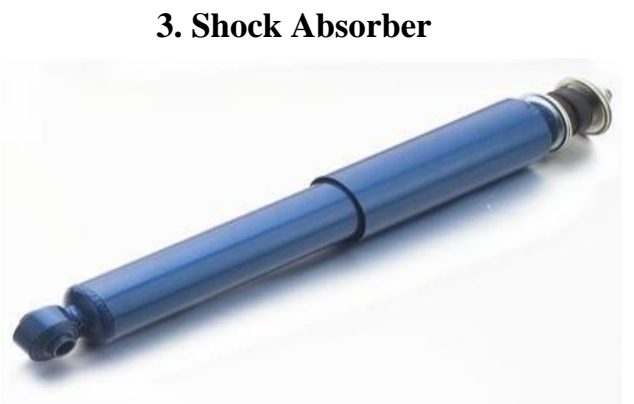

Fig. 1. A shock absorber

A shock absorber is a mechanical or hydraulic device designed to absorb and damp shock impulses, this by converting the kinetic energy of the shock is transferred into another form of energy which is usually heat energy and is then dissipated. Shock absorbers reduce the sudden jerks when traveling over rough ground, leading to improved ride quality and vehicle handling

\section{Comparison between Leaf Springs and Coils?}

A leaf spring suspension is made of long strip or a series of strips of steel attached at both ends to the frame and suspending the axle in the middle. The side profile of the leaf spring is that of a half ellipse and rectangular cross-sectional view. Coil springs as the name suggests, resembles a helix in appearance. It is situated between the axle and the lower control arm and the 
chassis. A coil is a mechanical device which is typically used to store energy and subsequently release it, to absorb shock, or to maintain an attractive or repulsive force between contacting surfaces.

\section{Coil Suspension}

A coil spring suspension offer wider range of suspension movement and offers the user a wider performance envelope through the suspension range than leaf springs. Almost all high performance vehicles use coil springs wherever possible as budget is usually not a constraint in high performance and competitive environments.

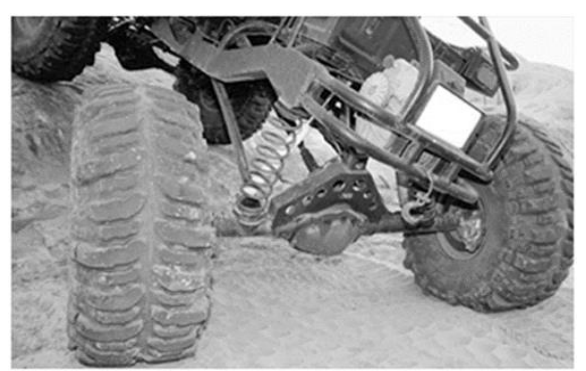

Fig. 2. Coil spring assembly

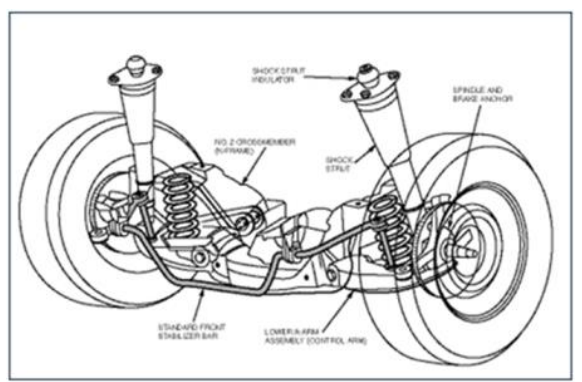

Fig. 3. Coil spring schematic diagram

\section{Leaf Spring Calculation}

- Total load $2 \mathrm{P}=20000 \mathrm{~N}$

- Number of leafs $n=4$

- Young's modulus $\mathrm{E}=2.1 * 10^{5}$

- Yield strength $=850 \mathrm{~N} / \mathrm{mm}^{2}$

- Total length of the leaf $2 \mathrm{l}=1000 \mathrm{~mm}$

- Half length of the leaf $1=500 \mathrm{~mm}$

- $\mathrm{P}=20000 /(4 * 2)$

- $\sigma b=12 p l / 6 t^{2}\left(3 n_{e}+2 n_{g}\right)$

- $850=12 * 2500 * 2500 / 50 *\left(\mathrm{t}^{2}\right)(3(1)+2(3))$

- $\mathrm{t}^{2}=12 * 2500 * 500 / 50 * 580 * 9$

- $\mathrm{t}=6.26 \mathrm{~mm}$

- $\mathrm{Y}=12 \mathrm{pl}^{3} / \mathrm{bt}^{3}(3 \mathrm{ne}+2 \mathrm{ng}) * \mathrm{E}$

- $\mathrm{Y}=12 * 2500 *(500)^{3} /\left(50 *(6.26)^{3}\left(\left(3(1)+2(3) * 2.1 * \mathrm{e}^{5}\right)\right)\right.$

- $\mathrm{Y}=162.33 \mathrm{~mm}$

- Camber radius $=0.5 * \mathrm{y}$

$$
\begin{aligned}
& =0.5 * 162.33 \\
& =81.75 \mathrm{~mm}
\end{aligned}
$$

- Radius of curvature

$$
\begin{aligned}
\mathrm{R} & =1^{2} / 2 * \mathrm{Y} \\
& =500^{2} / 2 * 162.33 \\
\mathrm{R} & =770.03 \mathrm{~mm}
\end{aligned}
$$

\section{Coil Suspension Calculation}

- Wire diameter (d): $12 \mathrm{~mm}$

- Mean diameter of spring (D): $75 \mathrm{~mm}$

- Outer diameter of spring (do): $87 \mathrm{~mm}$

- Free length of spring (1): $210 \mathrm{~mm}$

- No of active coils (i): 6

- Pitch (p): $30 \mathrm{~mm}$

Table 1

Quick comparison of leaf springs and others

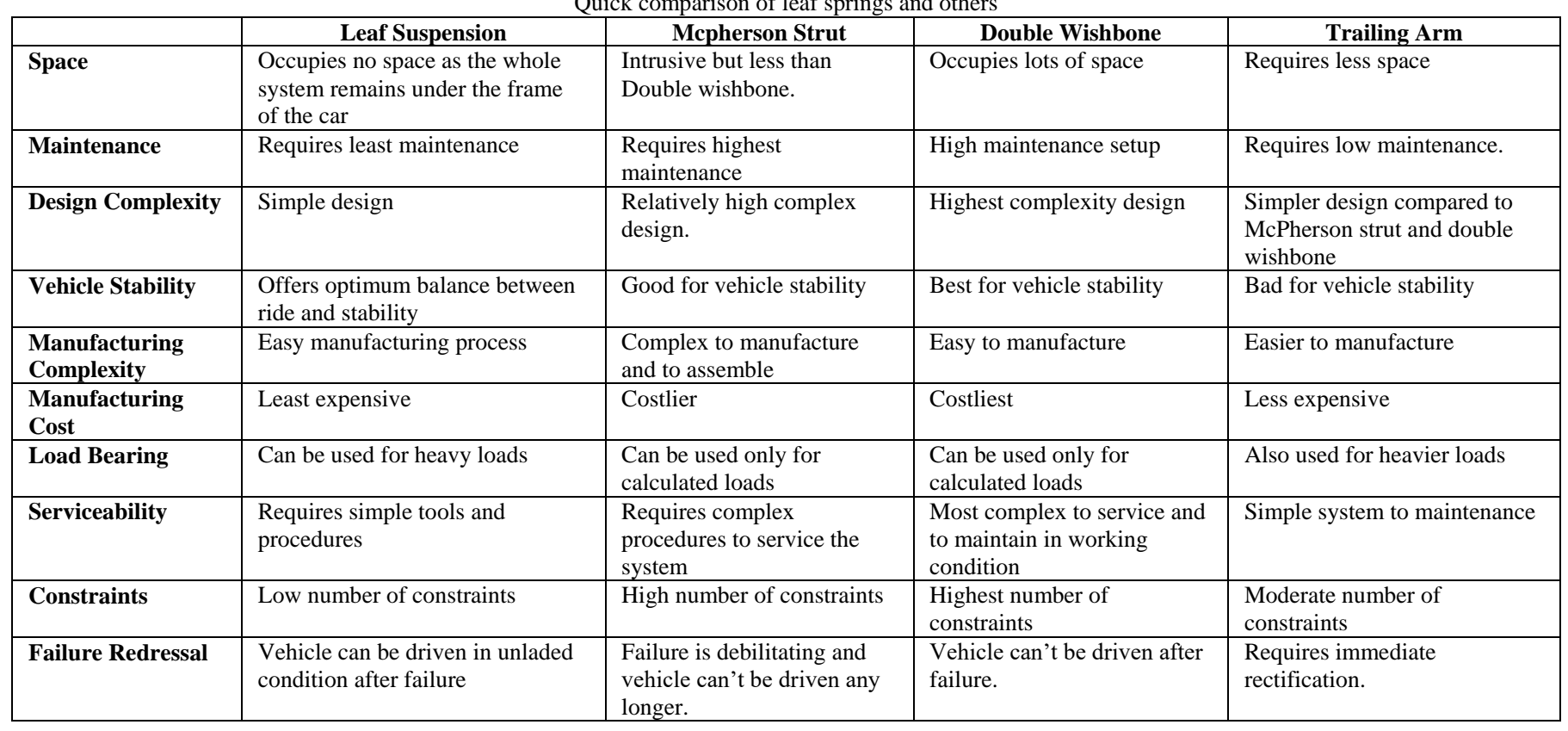


- $\quad$ Spring index (c) 6.25

- $\quad$ Stress factor $(\mathrm{K}) 1.24$

- $\quad$ Max shear stress $\left(\tau_{\max }\right) 342.5 \mathrm{Mpa}$

- Max deflection $\left(\gamma_{\max }\right) 28.5 \mathrm{~mm} 32.5 \mathrm{~mm}$

- $\quad$ Spring stiffness (k) 90.90 N/mm 76.92 N/mm spring (F): $2500 \mathrm{~N}$

\section{Design Report}

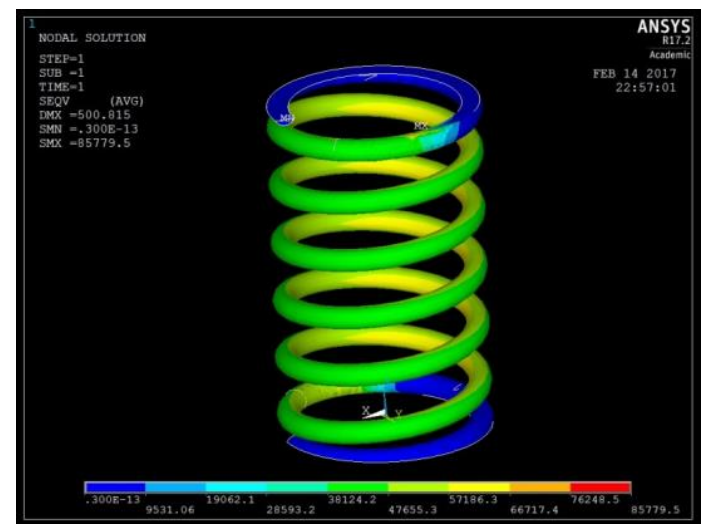

Fig. 4. Coil spring analysis

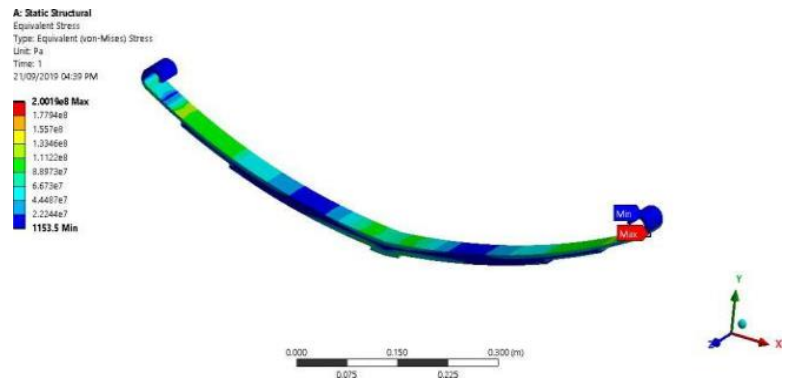

Fig. 5. Leaf spring FEA analysis

9. Conclusion

This paper presented design and manufacturing of leaf and coil suspension.

\section{References}

[1] Design data book, P. S. G. Tech.

[2] R. S. Kurmi, "Design of machine elements." 